BLS 34, No 1 2008. DOI: http://dx.doi.org/10.3765/bls.v34i1.3575

(published by the Berkeley Linguistics Society and the Linguistic Society of America)

\title{
Sluicing in Bahasa Indonesia, P-Stranding, and Interface Repair ${ }^{1}$
}

\author{
YOSUKE SATO \\ University of Arizona, Tucson
}

\section{Introduction}

This paper provides evidence that the P-stranding pattern in Bahasa Indonesia (BI) poses a counterexample to the P-Stranding Generalization proposed by Merchant (2001) in favor of his analysis of sluicing as the product of whmovement followed by TP deletion at PF. I first provide two arguments, based on the distribution of the question marker -kah (Fortin 2007) and the lack of the complementizer yang with wh-questions with non-nominal fronted wh-words that sluicing in $\mathrm{BI}$ is derived by regular wh-movement, as in English wh-questions. I propose that the three-way contrast between English, French, and BI with respect to P-stranding under $w h$-questions and sluicing is naturally derived from independently motivated assumptions concerning the percolation of the $[+\mathrm{wh}]$ feature of the DP onto the PP (Chomsky 1972), D-to-P incorporation (Law 1998, van Riemsdijk 1998), and the recent idea of interface repair (Merchant 2001, Lasnik 1999, 2001, 2005, 2007, Fox and Lasnik 2003, Boeckx and Lasnik 2006).

\section{Merchant's (2001) Theory of Sluicing and the P-Stranding Generali- zation}

Drawing on the data and analysis presented in Ross (1969), Merchant (2001) proposes that the sluicing construction as in (1a) is derived by the regular whmovement of the $w h$-remnant followed by TP deletion, as shown in (1b).

(1) a. Somebody just left. — Guess who.

b. Somebody just left. — Guess [CP $\mathrm{who}_{\mathrm{i}} \ldots \ldots$

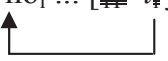

\footnotetext{
${ }^{1}$ This paper is based on the third chapter of my dissertation (Sato 2008). Earlier versions of this paper were presented at the Thirty-Third Annual Meeting of the Berkeley Linguistic Society and at the University of Arizona. I thank Heidi Harley, Andy Barss, Andrew Carnie, Cati Fortin, Mosa Hulden, Simin Karimi, and David Medeiros for valuable discussions on earlier drafts of this paper. Special thanks to Dwi Hesti Yuliani for sharing her knowledge of Bahasa Indonesia with me. The following abbreviations are used in this paper: Dem $=$ Demonstrative, $F o c=$ Focus, $\mathrm{Neg}=$ Negation, and $Q=$ Question.
} 


\section{Yosuke Sato}

Merchant adduces a wide variety of syntactic and morphological effects such as case-matching, number agreement, and so on, many of them mentioned in Ross (1969), to support this movement plus TP deletion analysis. One of the most convincing arguments for this analysis comes from what he calls the P-Stranding Generalization (PSG) stated as in (2).

(2) Preposition-Stranding Generalization/PSG (Merchant 2001:92)

A language $L$ will allow preposition stranding under sluicing iff $L$ allows preposition stranding under regular wh-movement.

The logic behind this generalization is clear. Under Merchant's analysis, sluicing is derived by regular $w h$-movement plus TP deletion. Thus, the availability of Pstranding under sluicing means that the same option should be independently available under regular wh-movement. Merchant surveys the P-stranding pattern both under $w h$-movement and sluicing in 24 languages to show that this generalization holds crosslinguistically, As is well known, English allows P-stranding both under $w h$-movement and sluicing, as shown in $(3 \mathrm{a}, \mathrm{c})$. Note that the same preposition can also be pied-piped along into [Spec, $\mathrm{CP}$ ], as shown in (3b).

(3) a. Who was he talking with?

b. With whom was he talking?

c. Peter was talking with someone, but I don't know (with) who.

(Merchant 2001:92)

This pattern falls out from Merchant's analysis because the P-less sluice in (3c) is derived when the preposition with is stranded within the TP, as in (3a). On the other hand, Romance languages such as French are non-P-stranding languages, as shown by the contrast between (4a) and (4b). Thus, French does not allow omission of the preposition under sluicing, as shown in (4c).

(4) a.* Qui est-ce qu' elle l'a offert à? 'Who has she offered it to?'

b. À qui l'a-t-elle offert?

to whom it-has-she offered

'To whom has she offered it?'

c. Anne l'a offert à quelqu'um, mais je ne sais pas *(à) qui. Anne it-has offered to someone but I Neg know not to whom 'Anne has offered it to someone, but I don't know (to) whom.'

$((4 a, c)$ are from Merchant 2001:98)

The type of language that is not predicted by the PSG, therefore, has syntactic whmovement, disallows P-stranding under this context, but nonetheless allows Pstranding under sluicing. I argue that BI is precisely of this type, as shown in (5). 


\section{P-Stranding in Bahasa Indonesia and Interface Repair}

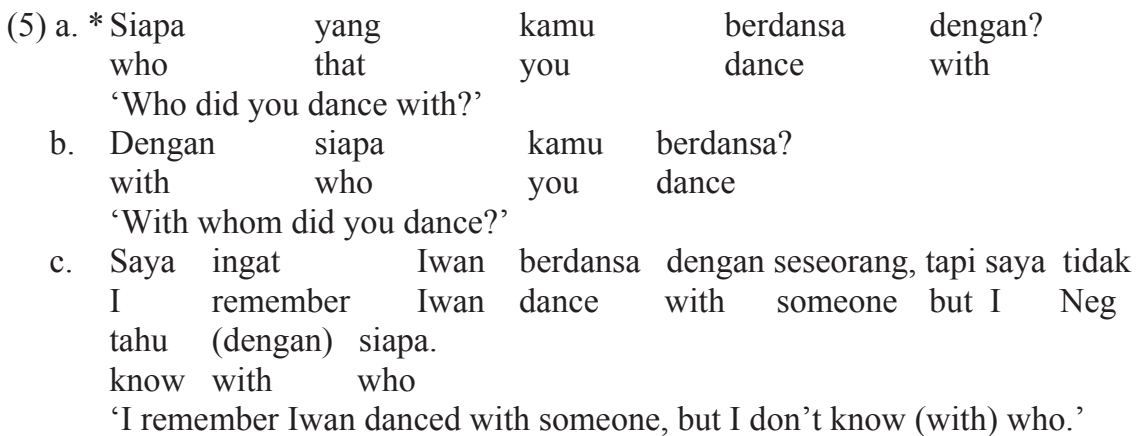

In the next section, I provide evidence that the P-stranding pattern observed in $(5 \mathrm{a}-\mathrm{c})$ provides a genuine counterexample to the PSG.

\section{The Syntax of Sluicing in Bahasa Indonesia}

Several languages have been reported in the literature that superficially contradict the PSG. They include Brazilian Portuguese (Almeida and Yoshida 2007; Rodriguez et al. 2007), Polish (Szczegielniak 2006), Malagasy (Potsdam 2003), Chinese (Wang 2006), and Serbo-Croatian (Stepanović 2008). These languages, however, have been shown to have alternative sources for sluicing, such as clefting, resumption, and P-omission at PF, hence do not necessarily undermine the PSG. See Fortin (2007) and Sato (2008:ch.3) for evidence against extending these analyses to BI sluicing. ${ }^{2}$ I argue, based on the distribution of the question morpheme -kah and the lack of the complementizer yang in wh-questions with fronted PPs, that the source for BI sluicing is wh-movement, as in English.

The first argument that BI sluicing is derived by regular wh-movement concerns the distribution of the question morpheme $-k a h$ in BI. Fortin (2007) observes that this particle can co-occur with the wh-pivot of the cleft but not with the $w h$-remnant of the sluice. This contrast is illustrated in $(6 a, b)$.

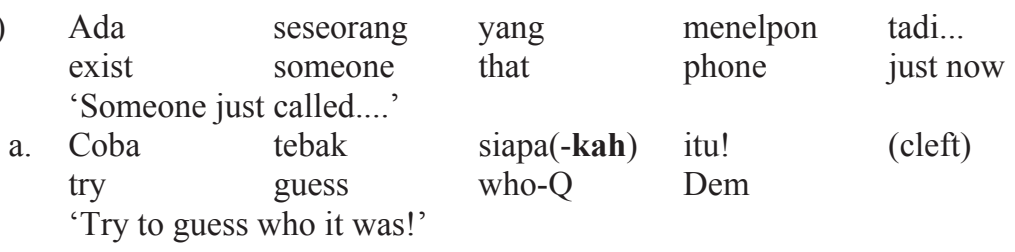

\footnotetext{
${ }^{2}$ Merchant (2001) develops several diagnostics to distinguish between genuine sluicing (derived by wh-movement followed by TP deletion) and pseudosluicing (derived by wh-movement followed by deletion of the copula and expletive subject). I am not going to discuss many important issues these diagnostics bring to bear on the nature of BI sluicing for reasons of space. See Fortin (2007), who provides results of applying those tests to BI clefts and sluicing. See Sato (2008:ch.3) for a critical discussion of whether these tests are applicable to BI to differentiate clefts from sluices.
} 


\section{Yosuke Sato}
b. Coba
tebak
try guess
'Try to guess who!'
c. Coba tebak siapa(-*kah) yang menelpon try guess who-Q that phone
siapa(-*kah)!
who-Q
(sluicing)
tadi! (wh-question)
just now

'Try to guess who just called now!'

(Fortin 2007:207, 208)

The contrast between (6a) and (6b) would not be accounted for by a cleft analysis of BI wh-questions. Thus, Cheng (1991) proposes the Clausal-Typing Hypothesis that the interrogative force of a statement must be marked either as a Q-particle in the scopal $\mathrm{C}$ or via the movement of a wh-operator into the specifier of the same $\mathrm{C}$ at S-Structure. When combined with the Economy of Derivation (Chomsky 1995), this hypothesis predicts that if a language has a Q-particle in its lexical inventory, that language should use it for all types of wh-questions, thereby excluding the need for a $w h$-phrase to undergo movement into the specifier of the $\mathrm{CP}$ and yielding the in-situ option across the board. Since BI allows both $w h$-insitu and overt $w h$-movement, Cheng argues that what appears to be an overt whmovement in this language is a reduced cleft where the expletive subject and copular are missing. Thus, examples as in (7a) would have the structure in (7b).

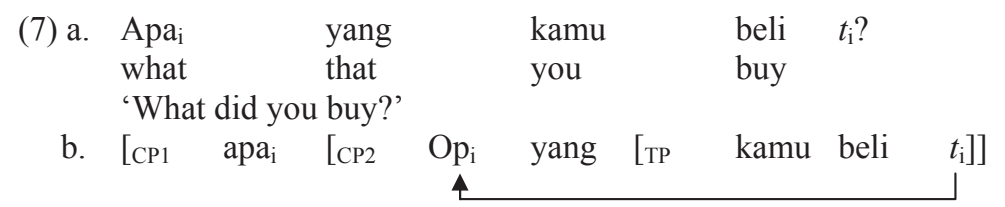

In (7b), the wh-phrase apa 'what' is base-generated in the specifier of CP1. The null operator undergoes movement from the object of the verb into the specifier of $\mathrm{CP} 2$. This analysis makes an incorrect prediction regarding the distribution of the Q-particle $-k a h$. If (6b) were derived by the cleft construction in (6a), then (6b) should also be able to allow the particle to occur with the wh-phrase siapa 'who'. This pattern, however, follows straightforwardly if BI has true wh-movement of the English type. Cheng's cleft analysis would need some extra stipulations to capture the distribution of $-k a h$ illustrated in (6a-c). Based on this consideration, I conclude that BI has true wh-movement, as in English.

The second argument that BI sluicing involves wh-movement concerns the obligatory lack of the complementizer yang in questions with fronted nonnominal elements. Cole et al. (to appear) propose that wh-questions with yang and those without have two different derivations; the former involve short focus movement of the wh-phrase from the post-copula position to the specifier of the matrix CP whereas the latter involve successive cyclic movement of the whphrase from its base position to the specifier of CP as in English wh-questions. Their analysis is illustrated in (8b) for the example in (8a) $(=7 a)$. 


\section{P-Stranding in Bahasa Indonesia and Interface Repair}

$\begin{array}{lllll}\text { (8) a. Apa } & \text { yang } & \text { kamu } & \text { beli } t_{\mathrm{i}} \text { ? } \\ \text { what } & \text { that } & \text { you } & \text { buy } & \end{array}$

b.

'What did you buy?'

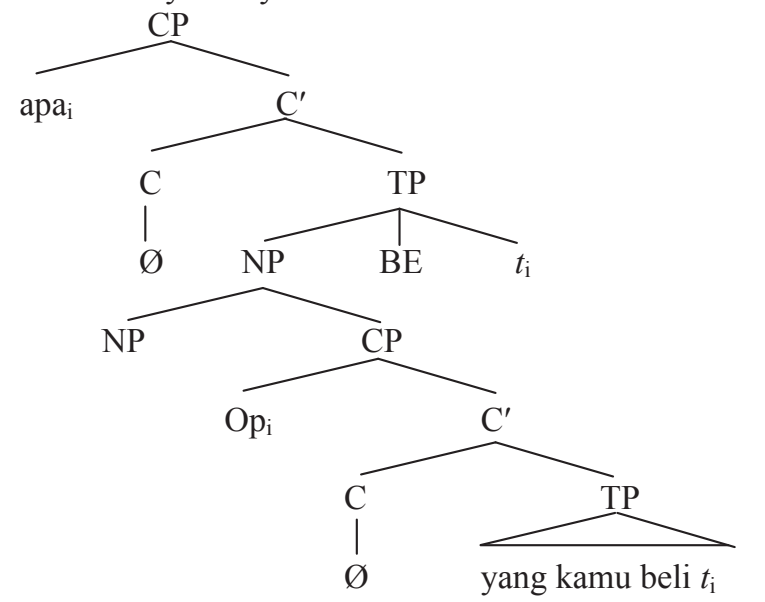

(modified from Cole et al. to appear:4)

In this derivation, there is movement of the null interrogative operator from the TP-internal position to the specifier of the embedded CP. apa 'what' undergoes focus movement from the position following the null copula (BE) to the specifier of the matrix CP. Cole et al.'s primary argument for this headless relative clause analysis of wh-questions with yang comes from the categorial restriction on interrogative elements that can be fronted in this type of question. Consider (9) and (10).

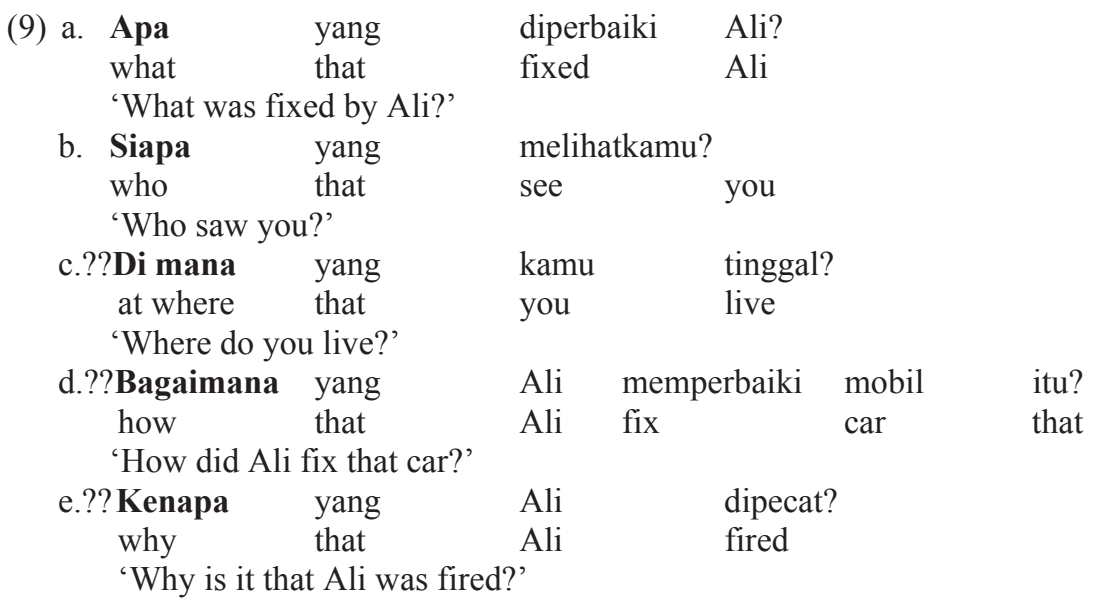

(BI: modeled after the Malay examples from Cole et al. to appear:6, 7) 
Yosuke Sato

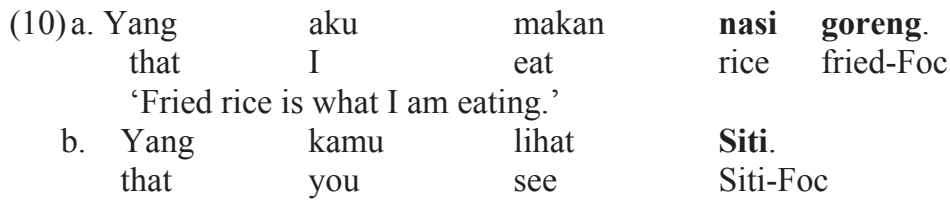

'Siti is what you see.'

c.?? Yang aku that I stay

di Kendal. 'The place that I live is in Kendal.'
d.?? Yang
Ali
memperbaiki
mobil itu
that
Ali fix
car that
dengan alat-nya.
with tool-his

at Kendal

'The way that Ali fixed that car is with his tool.'
e.?? Yang
Ali
dipecat
karena
dia ceroboh.
that
Ali fired
because
he

'Why Ali was fired is because he was careless.'

(BI: modeled after the Malay examples from Cole et al. to appear:9)

It is clear from (9) that, when wh-questions are formed with yang, only questions with nominal wh-phrases such as apa 'what' and siapa 'who' are well-formed. This categorial restriction would remain mysterious under the common analysis of wh-questions in languages like English as fronting of an interrogative phrase into the specifier of the matrix $\mathrm{CP}$, since no such restriction would be imposed on the kind of elements to be fronted. This observation, by contrast, directly follows if the underlying structure of yang-questions is a headless relative clause, because the same restriction is independently observed in (10a-e).

As Cole et al. note, however, their headless relative clause analysis would only work for $w h$-questions with nominal $w h$-phrases. This point is emphasized by their conclusion (Cole et al. to appear: 26) that "questions without yang involve potentially long distance movement of the WH word itself." Consider (11).

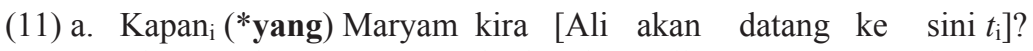
when that Maryam think Ali will come to here 'When does Miriam think that Ali will come here?'

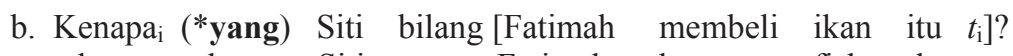
why that Siti say Fatimah buy fish that 'Why does Siti say that Fatimah bought that fish?'

(BI: modeled after the Malay examples from Cole et al. to appear:27)

(11) shows that wh-questions with non-nominal wh-elements such as kapan 'when' and kenapa 'why' do not co-occur with yang. For Cole et al., the lack of yang means that the questions are derived by regular wh-movement of an interrogative phrase into the specifier of $\mathrm{CP}$. Then, the obligatory absence of this complementizer in (9c) indicates that the $w h$-question with the fronted PP cannot 


\section{P-Stranding in Bahasa Indonesia and Interface Repair}

be analyzed as the headless relative clause because there is an independent restriction that the head of such a clause must be nominal wh-phrases such as apa 'what' and siapa 'who'. Thus, at least the PP wh-question in BI is derived by regular $w$ h-movement, as in English.

With the two arguments above in mind, consider again the examples in (5). I have shown above that the BI sluicing (with PP remnants) is derived by regular wh-movement of the remnant followed by TP deletion. Therefore, the P-stranding pattern in BI presents the first genuine counterexample to the PSG.

\section{P-Stranding under Sluicing and Interface Repair}

\subsection{Feature Percolation, D-to-P Incorporation, and Interface Repair}

The analysis proposed below draws on three independently motivated assumptions. Let us quickly review each of them before we move onto the analysis in section 3.2 .

First, I claim that there is percolation of the $[+w h]$ feature of the DP onto the PP. This idea was proposed by Chomsky (1972) to answer a criticism raised by Postal (1972). Postal observes that, if movement is successive-cyclic, it would predict that the preposition should be able to be stranded in any one of the specifiers of intermediate CPs. The ungrammatical examples in $(12 \mathrm{~d}, \mathrm{e})$ show that this prediction is incorrect.

(12) a. I believe Mary thinks Joan talked to someone.

b. Who do you believe Mary thinks Joan talked to?

c. To whom do you believe Mary thinks Joan talked?

d. * Who/Whom do you believe to Mary thinks Joan talked?

e. * Who/Whom do you believe Mary thinks to Joan talked?

(Postal 1972:213)

The relevant generalization here is that prepositions in English must either be stranded in situ or pied-piped into the specifier of the matrix CP. Chomsky argues that this generalization falls out if the [+wh] feature of the $w h$-word can optionally percolate onto its dominating PP in English, in the manner seen in (13a, b).

(13)

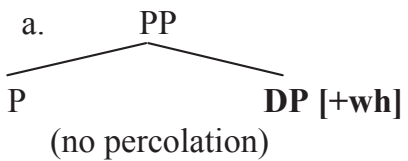

b.

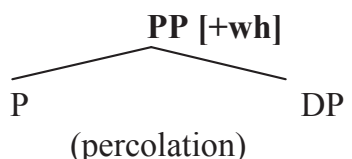

When the $[+w h]$ feature remains in situ, as in (13a), the closest element from the perspective of the interrogative $\mathrm{C}$ is the DP. This option yields the stranded Pstructure in (12b). When the same feature percolates, as in (13b), it is the PP now marked with that feature that is attracted by the interrogative $\mathrm{C}$. This option yields the pied-piping structure in (12c). Notice that, under this feature-based analysis, there is no way in which the preposition can be stranded in intermediate sites 


\section{Yosuke Sato}

because the decision as to whether the relevant feature is percolated or not is made when the derivation constructs the PP, as shown in (13a, b).

The second assumption concerns D-to-P incorporation. It is well known that, in Romance languages such as French, a preposition sometimes coalesces with the following determiner element into a suppletive form, as in (14).

$$
\begin{aligned}
& \text { Jean a parlé du sujet le plus difficile. (French) } \\
& \text { Jean have talked about-the subject the most difficult } \\
& \text { 'Jean talked about the most difficult subject.' }
\end{aligned}
$$

In (14), the preposition de coalesces with its following determiner le to yield a suppletive form $d u$. Law (1998) (see also Beerman 1990 and van Riemsdijk 1998 for German) propose that there is a syntactic constraint on suppletion, as defined in (15).

Syntactic Constraint on Suppletion (Law 1998:22)

Elements undergoing suppletive rules must form a syntactic unit $\mathrm{X}^{0}$.

This constraint states that determiners must incorporate onto their governing prepositions to be reanalyzed in the post-syntactic component as a suppletive element. Of course, there are cases (e.g. de la in French) where D-P coalescence does not occur, but it is not likely that general syntactic operations such as incorporation should be constrained by this type of unpredictable morpholexical gap. Rather, a more plausible analysis would be one in which D-to-P incorporation occurs across the board in French, whether or not its effects are morphophonologically realized in the form of D-P coalescence.

The final and most important idea I pursue in this paper is that of interface repair. This idea has been circulated since the late 1960s, when Ross (1969) observed that the sluicing transformation ameliorates island-violations that would otherwise yield ungrammatical sentences. Following Chomsky (1972), Merchant (2001) proposes a revision of Ross' idea by arguing that sluicing ameliorates certain island violations because they essentially constitute islands only at the PF interface. Further elaborating on this point, Boeckx and Lasnik (2006) claim that both derivational and representational constraints must be admitted into the theory of grammar on the grounds that $w h$-island effects can be repaired whereas superiority violations cannot. This notion of interface repairs plays a crucial role in the analysis proposed below.

\subsection{Towards an Etiology of the Typology of P-Stranding}

I propose a parametric analysis of the typology of P-stranding at the SyntaxPhonology Interface that draws on the three independently motivated assumptions introduced in the previous subsection, summarized in (16). ${ }^{3}$

\footnotetext{
${ }^{3}$ Many thanks to Heidi Harley (personal communication, April 2008) for suggesting the analysis
} 


\section{P-Stranding in Bahasa Indonesia and Interface Repair}

(16) Table 1: The Parametric Theory of P-Stranding at the S-P Interface

\begin{tabular}{|c|c|c|}
\hline Languages & $\begin{array}{l}{[+ \text { wh }] \text { feature percolation }} \\
\text { from the D to PP }\end{array}$ & $\begin{array}{l}\text { D-to-P incorporation } \\
\text { in the syntax }\end{array}$ \\
\hline English & OPTIONAL & NO \\
\hline BI & OBLIGATORY & NO \\
\hline French & OBLIGATORY & YES \\
\hline
\end{tabular}

Consider first why English allows P-stranding both under wh-movement and sluicing. English allows P-stranding under wh-questions because this language has the option of not percolating the $[+w h]$ feature of the nominal complement of $\mathrm{P}$ onto the PP. When this option is chosen, the interrogative $\mathrm{C}$ attracts the whphrase, onto its specifier, deriving the P-stranding configuration. When the [+wh] feature is percolated, the pied-piped counterpart results. English allows Pstranding under sluicing because the preposition left behind within the PP is elided by deletion of the TP that contains this constituent.

How about BI? This language does not allow P-stranding under wh-questions because the $[+$ wh] feature of the nominal complement of $\mathrm{P}$ must percolate onto the PP. As a result, the PP is attracted to the specifier of CP. The question is, then, why $\mathrm{P}$-stranding does not yield ungrammaticality under sluicing. It is at this point that the role of the syntax-external phonological system plays a critical role in remedying imperfections created by syntactic computation. Consider the derivations in $(17 \mathrm{a}, \mathrm{b})$ for the grammatical P-less sluice in $(5 \mathrm{c})$.

(17)a.S-P Interface (No Repair)

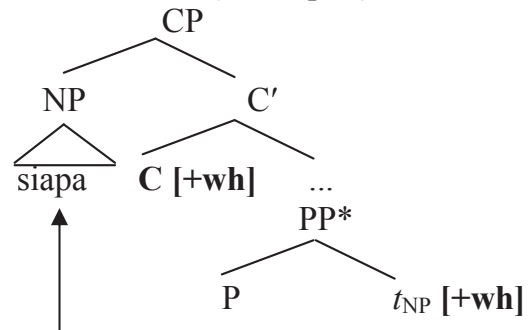

interface violation detected b. S-P Interface (Repair)

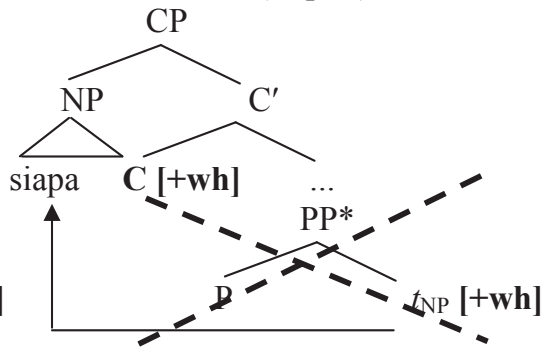

interface violation repairable

I propose that a) a failure of the $[+w h]$ feature to percolate is repaired at the syntax-phonology interface and that b) a representational constraint to verify percolation rules out the offending PP at the interface. If the offending PP remains at $\mathrm{PF}$, the representational constraint is violated, as shown in (17a). If the offending PP is deleted at the interface, as shown in (17b), the representational constraint has nothing to apply to. This derivation, thus, can still converge at the interface.

presented in this subsection and very helpful follow-up discussion on issues related to the analysis. 


\section{Yosuke Sato}

Let us finally consider the French P-stranding pattern. French does not permit P-stranding under $w h$-movement as in $\mathrm{BI}$ because the [+wh] feature obligatorily percolates onto the PP that dominates the wh-phrase. As shown in (4c), French also does not allow P-less sluices. What is crucial here is that languages like French have D-to-P incorporation, as we saw earlier in section 3.1. Consider the derivations in $(18 \mathrm{a}, \mathrm{b})$ for the ungrammatical P-less sluice in $(4 \mathrm{c})$.

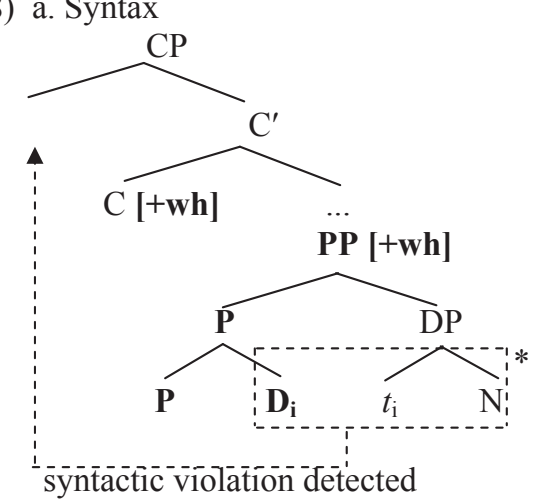

b. Syntax-Phonology Interface

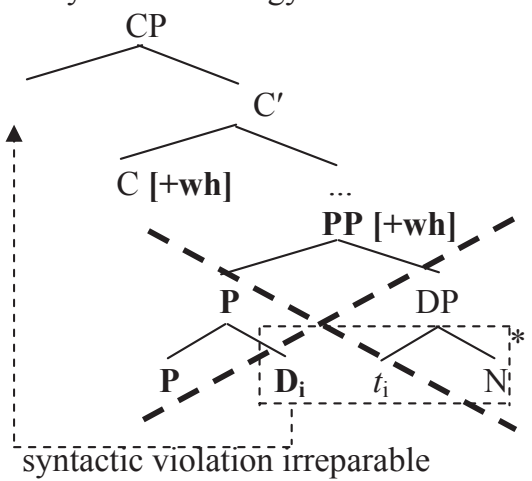

In (18a), the $\mathrm{D}$ head undergoes syntactic incorporation into the $\mathrm{P}$ in accordance with Law's constraint given in (15). The $[+w h]$ feature of the moved D head percolates onto the dominating PP. This derivation crashes because, when the C with the $[+w h]$ feature attracts the element with the matching feature, the DP is no longer a syntactic constituent, hence cannot be attracted by C. Notice that the Pless sluice could still be derived if the $\mathrm{D}$ head underwent incorporation to be attracted by the $\mathrm{C}$ head. However, this possibility is blocked since this excorporation would cause the Empty Category Principle-like violation; the trace of the excorporating element cannot be properly licensed. The point here is that whatever derivation could possibly yield the P-stranding sluice in French crashes because of the interaction of purely syntactic/derivational constraints on D-to-P incorporation. Therefore, when (18a) reaches the interface, as illustrated in (18b), it is simply too late to repair violations associated with D-to-P incorporation because the violations incurred are strictly syntactic. More specifically, once the preposition with the unvalued feature (e.g. D-feature) is introduced into the derivation, it must start probing and attract the matching goal with the D-feature since that is the driving force for syntactic derivation: this mechanical computation is hard-wired into the definition of Agree, Match, and Move. Thus, the violation of D-to-P incorporation is simply impossible in the minimalist vision of syntactic derivation. This is different from the failure of feature percolation, which is an interface violation whose severity could vary from language to language, and can be undone by deletion at the PF interface. Thus, syntactic representations that involve this violation can still converge, as we saw in $\mathrm{BI}$. 


\section{P-Stranding in Bahasa Indonesia and Interface Repair}

\section{Concluding Remarks}

This paper has proposed that the notion of interface repair by way of deletion plays a crucial role in the proposed account of the three-way contrast between English, BI, and French with respect to P-stranding. The most important theoretical claim of the proposed analysis is that the phonological component can repair certain illicit configurations created by failure of $[+w h]$ feature percolation by deleting them. However, interfaces are neither omniscient nor omnipotent; it cannot undo "mistakes" concerning D-P coalescence that are syntactically/derivationally conditioned, since the syntax is so constructed to be unable to produce such violations in the first place. The proposed analysis, therefore, provides support for the general idea that interface components can conduct domain-specific operations to repair certain imperfections but only within the curve parametrically defined by universal syntactic mechanisms. See Sato (2008) for further extensions of this view of linguistic interfaces, as applied to semantics (wh-in-situ) and morphology (reduplication).

\section{References}

Almeida, Diogo, and Masaya Yoshida. 2007. A Problem for the Preposition Stranding Generalization. Linguistic Inquiry 38(2): 349-362.

Beerman, Dorothee. 1990. Semantic and Syntactic Constraints on German Determiner Movement within the Prepositional Phrase. Master's Thesis, University of Texas, El Paso.

Boeckx, Cedric, and Howard Lasnik. 2006. Intervention and Repair. Linguistic Inquiry 37 (1): 150-155.

Cheng, Lisa. 1991. On the Typology of Wh-Questions. Ph.D.diss., MIT.

Chomsky, Noam. 1972. Some Empirical Issues in the Theory of Transformational Grammar. In S. Peters, ed., Goals of Linguistic Theory, 63-130. Winston: Englewood Cliffs.

Chomsky, Noam. 1995. The Minimalist Program. Cambridge, MA: MIT Press.

Cole, Peter, Gabriella Hermon, and Norhaida Aman. To appear. Clefted Questions in Malay. In D. Gil, ed., Malay/Indonesian Linguistics. London: Curzon.

Fortin, Catherine. 2007. Indonesian Sluicing and Verb Phrase Ellipsis: Description and Explanation in a Minimalist Framework. Ph.D.diss., U. of Michigan.

Fox, Danny, and Howard Lasnik. 2003. Successive-Cyclic movement and Island Repair: The Difference between Sluicing and VP-Ellipsis. Linguistic Inquiry 34(1): 143-154.

Lasnik, Howard. 1999. On Feature Strength: Three Minimalist Approaches to Overt Movement. Linguistic Inquiry 30 (2): 197-217.

Lasnik, Howard. 2001. When Can You Save a Structure by Destroying it? In M.J. Kim and U. Strauss, eds., Proceedings of North East Linguistic Society 31, 301-320. University of Massachusetts, Amherst: Graduate Linguistic Student Association (GLSA). 
Yosuke Sato

Lasnik, Howard. 2005. Speculations on P-Stranding. Class lecture handout, Linguistic Society of America, MIT/Harvard University. July 18-August 3 [http://www.ling.umd.edu/ lasnik/LSA\%20course/Lasnik\%20LSA\%20HO\% 20Sect $\% 202 \% 20$ Appendix $\% 20$ P-stranding.pdf]

Lasnik, Howard. 2007. On Ellipsis: The PF Approach to Missing Constituents. In A. Conroy, C. Jing, C. Nakao, and E. Takahashi, eds., University of Maryland Working Papers in Linguistics 15, 143-153. College Park: UM Linguistics.

Law, Paul. 1998. A Unified Analysis of P-Stranding in Romance and Germanic. In P. Tamanji and K. Kusumoto, eds., Proceedings of North East Linguistic Society 28, 219-234. University of Massachusetts, Amherst: GLSA.

Merchant, Jason. 2001. The Syntax of Silence: Sluicing, Islands, and the Theory of Ellipsis. Oxford: Oxford University Press.

Postal, Paul. 1972. On Some Rules that are not Successive Cyclic. Linguistic Inquiry 3(2): 211-222.

Potsdam, Eric. 2003. Evidence for Semantic Identity under Ellipsis from Malagasy. In M. Kadowaki and S. Kawahara, eds., Proceedings of North East Linguistic Society 33, 285-302. University of Massachusetts, Amherst: GLSA.

Rodrigues, Cilene, Andrew Nevins, and Luis Vicente. 2007. Cleaving the Interactions between Sluicing and Preposition Stranding. Ms., Unicamp, Harvard, and University of California, Santa Cruz. [To appear in Proceedings of Going Romance 20, Vrije Universiteit.]

Ross, John. 1969. Guess Who. In R. Binnick, A. Davison, G. Green, and J. Morgan, eds., Papers from the 5th Regional Meeting of the Chicago Linguistic Society, 252-286. Chicago: Chicago Linguistic Society.

Sato, Yosuke. 2008. Minimalist Interfaces: Selected Issues in Indonesian and Javanese. Ph.D.diss., University of Arizona, Tucson.

Stepanović, Sandra. 2008. P-Stranding under Sluicing in a Non-P-Stranding Language? Linguistic Inquiry 39 (1): 179-190.

Szczegielniak, Adam. 2006. All Sluices up, but no Alleviation in Sight. Ms., Harvard University.

van Riemsdijk, Henk. 1998. Head Movement and Adjacency. Natural Language and Linguistic Theory 16(3): 633-678.

Wang, Chyan-An. 2006. Sluicing and Resumption. Paper presented at the 18th Annual Meeting of the Northeast Linguistic Society. [To appear in Proceedings of North East Linguistic Society 37, University of Massachusetts, Amherst, GLSA]

Department of Linguistics

Douglass 200E,

University of Arizona

Tucson, AZ 85721-0028

yosukes@email.arizona.edu 